\title{
Association of blood glucose level and hypertension in Elderly Chinese Subjects: a community based study
}

\author{
Qun Yan ${ }^{1+}$, Dongmei Sun ${ }^{1,2+}, \mathrm{Xu} \mathrm{Li}{ }^{1}$, Guoliang Chen², Qinghu Zheng ${ }^{2}$, Lun Li ${ }^{2}$ Chenhong $\mathrm{Gu}^{2}$ and Bo Feng ${ }^{1 *}$
}

\begin{abstract}
Background: There is a scarcity of epidemiological researches examining the relationship between blood pressure (BP) and glucose level among older adults. The objective of the current study was to investigate the association of high BP and glucose level in elderly Chinese.

Methods: A cross-sectional study of a population of 2092 Chinese individuals aged over 65 years was conducted. Multiple logistic analysis was used to explore the association between hypertension and hyperglycemia. Independent risk factors for systolic and diastolic BP were analyzed using stepwise linear regression.

Results: Subjects in impaired fasting glucose group (IFG) $(n=144)$ and diabetes $(n=346)$, as compared with normal fasting glucose (NFG) $(n=1277)$, had a significant higher risk for hypertension, with odds ratios (ORs) of 1.81 (95\% Cl, 1.39-2.35) $(P=0.000)$ and $1.40(95 \% \mathrm{Cl}, 1.09-1.80)(P=0.009)$, respectively. Higher fasting plasma glucose $(F P G)$ levels in the normal range were still significantly associated with a higher prevalence of hypertension in both genders, with ORs of $1.24(95 \% \mathrm{Cl}, 0.85-1.80), R^{2}=0.114, P=0.023$ in men and $1.61(95 \% \mathrm{Cl}, 1.12-2.30), R^{2}=0.082, P=0.010$ in women, respectively, when compared with lower FPG. Linear regression analysis revealed FPG was an independent factor of systolic and diastolic BP.

Conclusions: Our findings suggest that hyperglycemia as well as higher FPG within the normal range is associated with a higher prevalence of hypertension independent of other cardiovascular risk factors in elderly Chinese. Further studies are needed to explore the relationship between hyperglycemia and hypertension in a longitudinal setting.
\end{abstract}

Keywords: Fasting plasma glucose, Diabetes, Hypertension, Cross-sectional study

\section{Background}

Metabolic syndrome is defined as the occurrence of 3 of any of the 5 following factors: abdominal obesity, elevated triglyceride (TG), low high-density lipoprotein cholesterol (HDL-c), elevated blood pressure (BP) and elevated fasting glucose level [1]. It is well known that metabolic syndrome increases the risk for morbidity and mortality from cardiovascular diseases [2, 3]. Actually, the coexistence of hypertension and diabetes alone confers 2-3 times the risk for cardiovascular morbidity and mortality as for people without diabetes $[4,5]$. Epidemiological research established that hypertension is

\footnotetext{
* Correspondence: fengbo@medmail.com.cn

${ }^{\dagger}$ Equal contributors

'Department of Endocrinology, Shanghai East Hospital, Tongji University

School of Medicine, 150 Jimo Road, Shanghai 200120, China

Full list of author information is available at the end of the article
}

more common in subjects with diabetes mellitus (DM) than in the general population [6,7]. On the other hand, higher BP is associated with increased risk of diabetes [8-12], even in individuals with normotension [7]. However, current studies evaluating the relationship of $\mathrm{BP}$ with blood glucose level were limited to age of younger [8-10], or from across the age spectrum [6, 7, 13], did not separate out the data of elderly subjects. Furthermore, referral-based samples in most were mainly with hyperglycemia and hypertension $[6,7,11,12]$. Some studies relied on self-reported DM or BP [8-10].

Considering the influence of hypertension or hyperglycemia on vascular disease and mortality are age-specific [13], we therefore conducted a cross-sectional survey study in a well-characterized community-based sample of individuals in East China aged over 65 to assess 
whether higher fasting plasma glucose (FPG) is independently associated with a higher prevalence of hypertension, and conversely, whether higher BP is associated with a higher prevalence of hyperglycemia in elder people.

\section{Methods}

\section{Population}

A cross-sectional study was conducted in Shanghai Pudong New Area between January 2012 and March 2012. Residents who had lived here over 5 years were recruited. Among the 2777 individuals who were aged over 65 year, 2250 subjects participated in the current study.

Inclusion criteria were: (i) men or women aged over 65 year; (ii) with no severe chronic disease or systemic disease; (iii) willing and able to give informed consent; and (iv) with complete data on key research variables. Subjects with medical diseases such as cardiac disease (heart failure), chronic liver and kidney dysfunction (including serum alanine aminotransferase $>120 \mathrm{IU} / \mathrm{l}$, and aspartate aminotransaminase $>80 \mathrm{IU} / \mathrm{l}$, and serum creatinine $>$ $2.0 \mathrm{mg} / \mathrm{dl}$ ), acute infection, severe systemic diseases (e.g., cancer) or Acquired Immune Deficiency Syndrome (AIDS) as well as patients who had secondary hypertension were excluded $(n=89)$. Those with incomplete data on key research variables were also excluded $(n=69)$. Subsequently, 2092 individuals (971 men and 1121 women) were included in the current analysis (Fig. 1).

All participants were screened with regard to medical history (i.e., smoking, alcohol consumption, and medical treatments). Current smokers were defined as those who currently smoke every day or some days and who reported having smoked over 100 cigarettes during their lifetimes. Alcohol consumption was defined as having up to 20-30 g of ethanol per day for men and up to 10-20 $\mathrm{g}$ of ethanol per day for women. Details of this survey have been reported previously [14]. Written informed consent was obtained from all participants.

\section{BP Measurements}

BP was measured using a mercury sphygmomanometer by an experienced physician. Subjects were in a seated position with an arm flexed at the level of the heart. After the cuff was wrapped around the upper arm with the cuff's lower edge one inch above the antecubital fossa, the cuff was rapidly inflated to $180 \mathrm{mmHg}$. Then air was released from the cuff at a rate of $3 \mathrm{~mm} / \mathrm{s}$. During this period, the physician listened carefully with a stethoscope while simultaneously observing the sphygmomanometer. The first knocking sound (Korotkoff) was the subject's systolic pressure. When the knocking sound disappeared, that was the diastolic pressure. BP was measured in either the right upper or left upper arm after each subject had been seated for at least $10 \mathrm{~min}$. The arm with the higher blood pressure would be measured twice. The average was used for analysis. If the difference of SBP or DBP between the twice was over $5 \mathrm{mmHg}$, it would be measured for the third time, and then the average of three times was used for analysis.

Hypertension was defined as systolic blood pressure (SBP) $\geq 140 \mathrm{mmHg}$ and/or diastolic blood pressure (DBP) $\geq 90 \mathrm{mmHg}$ or reported receiving antihypertensive medication. Participants who were diagnosed hypertensive for the first time during this survey were called new-onset

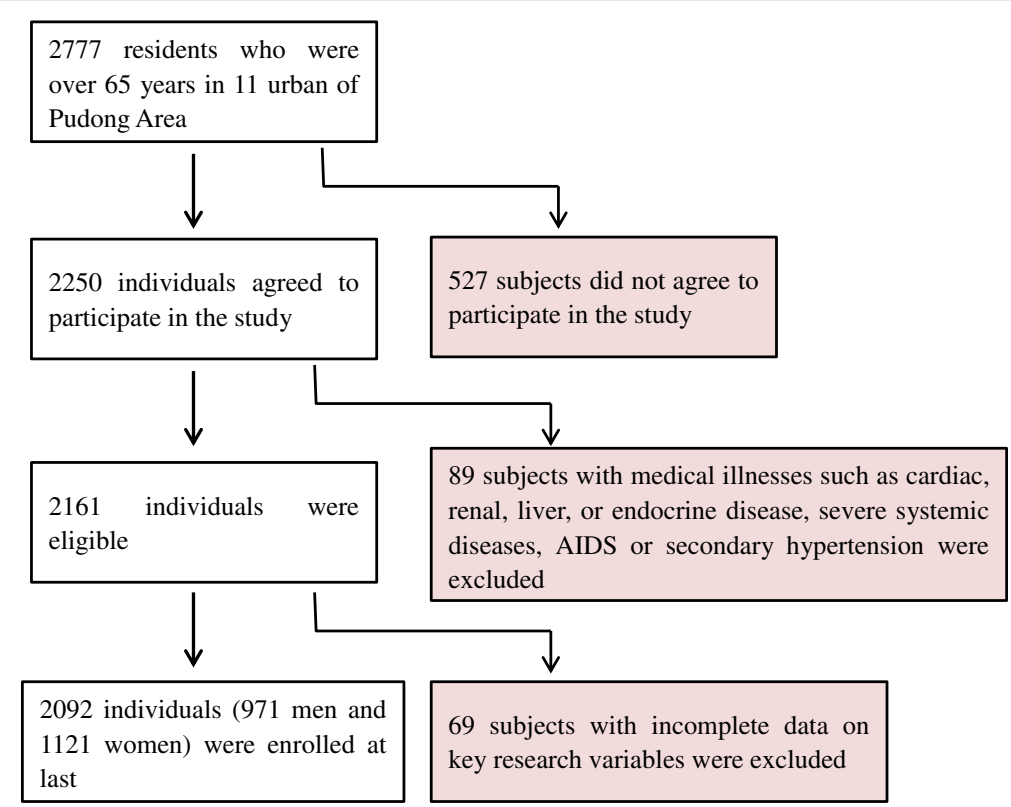

Fig. 1 Study design and participant flow diagram for the present study 
hypertension; participants who had a history of hypertension were called previously-diagnosed hypertension. Highnormal BP was defined as not having hypertension, and with SBP $120-139 \mathrm{mmHg}$ or DBP $80-90 \mathrm{mmHg}$; normal $\mathrm{BP}$ included SBP $<120 \mathrm{mmHg}$ and $\mathrm{DBP}<80 \mathrm{mmHg}$ and with no antihypertensive treatment [15].

\section{DM Ascertainment}

Participants were considered to have DM if fasting blood glucose $\geq 7.0 \mathrm{mmol} / \mathrm{L}$ or reported using insulin or oral hypoglycemic medication. Participants who were diagnosed DM for the first time during this survey were called new-onset DM, participants who had a history of DM were called previously-diagnosed DM. Normal fasting glucose (NFG) was defined as $\mathrm{FPG}<6.1 \mathrm{mmol} / \mathrm{L}$. Impaired fasting glucose (IFG) was defined as $\mathrm{FPG} \geq$ $6.1 \mathrm{mmol} / \mathrm{L}$ but $<7.0 \mathrm{mmol} / \mathrm{L}$ according to $\mathrm{WHO}$ criteria, 1999 [16].

\section{Covariates}

Height and weight of all subjects were measured in light clothes with no shoes. Waist circumference was measured at the level midway between the lower rib margin and the iliac crest. Body mass index (BMI) was calculated as weight $(\mathrm{kg})$ divided by the square of height $(\mathrm{m})$.

Blood samples were collected from venous blood after overnight fasting, and FPG, total cholesterol and triglyceride were measured. Glucose measurement was done in a central lab in Shanghai East Hospital. Plasma fasting glucose level was determined in $\mathrm{NaF}$ preserved plasma using the glucose oxidase method by automatic analyzer, Accurizer Autochem 400 (Affinitech, China).

\section{Statistical analysis}

Continuous data were summarized by the mean \pm SD or median, and categorical data by number (percentages). All of the continuous data had skewed distribution even after logarithmically transformed. Mann-Whitney test (for data that was not normally distributed) and Chisquare test (for data that were categorical variables) were used to compare the differences between the Men and Women groups.

The participants were divided into 4 groups according to FPG levels: NFG $(n=1277)$, IFG $(n=144)$, New-onset DM $(n=325)$, and previously-diagnosed DM $(n=346)$. Binary logistic analysis was used to examine the association of hyperglycemia status with hypertension. Then NFG group was further divided into two subgroups according to the median FPG level by sex. Multiple logistic analyses were used to explore the associations between hypertension and hyperglycemia. Independent risk factors for systolic and diastolic pressure were analyzed using stepwise linear regression.

\section{Results}

\section{Clinical characteristics}

The baseline characteristics of the study population by sex were shown in Table 1 . The study population consisted of 2092 (971 men and 1121 women, mean age 72.8 and 73.6 years, respectively). The prevalence of total $\mathrm{DM}$ in men and women were $23.1 \%$ and $23.7 \%$, respectively $(P=0.381)$. The prevalence of hypertension in men and women were $45.3 \%$ and $48.5 \%$, respectively $(P=0.077)$. There were no significant differences in the prevalence of IFG and high-normal BP between the sexes. Other metabolic and anthropometric variables, except for BMI and FPG, were significantly different between the sexes (all $P<0.05$ ).

\section{Association of FPG and risk of hypertension}

After adjusting for sex, age, smoking, alcohol using, BMI, TG and TC levels, subjects in IFG and previouslydiagnosed DM, as compared with NFG $(<6.1 \mathrm{mmol} / \mathrm{L})$, had a significant higher risk for hypertension in whole sample, with odds ratios (OR) of 1.81 (95\% CI, 1.392.35) $(P=0.000)$ and $1.40(95 \% \mathrm{CI}, 1.09-1.80)(P=$ $0.009)$, respectively. Subjects in the IFG group were also associated with an increased OR of new-onset hypertension (OR 1.68 [95 \% CI, 1.18-2.41], $P=0.004$ ) when comparing with NFG. Of note, there were strong

Table 1 Baseline characteristics by sex

\begin{tabular}{|c|c|c|c|}
\hline Parameters & Men & Women & $P$ value \\
\hline Number & 971 & 1121 & \\
\hline Age(y) & $72.8 \pm 6.4$ & $73.6 \pm 7.0$ & 0.027 \\
\hline Current smoker n (\%) & $215(22.1 \%)$ & $27(2.4 \%)$ & 0.000 \\
\hline Alcohol consumption n (\%) & $143(14.7 \%)$ & $17(1.5 \%)$ & 0.000 \\
\hline T2DM n (\%) & $224(23.1 \%)$ & $266(23.7)$ & 0.381 \\
\hline IFG n (\%) & $142(14.6 \%)$ & $167(14.9 \%)$ & 0.455 \\
\hline Hypertension n (\%) & $440(45.3 \%)$ & $544(48.5 \%)$ & 0.077 \\
\hline High-normal BP n (\%) & $427(44.0 \%)$ & $489(43.6 \%)$ & 0.453 \\
\hline $\mathrm{BMI}\left(\mathrm{kg} / \mathrm{m}^{2}\right)$ & $23.7 \pm 3.3$ & $23.9 \pm 3.8$ & 0.316 \\
\hline$W C(\mathrm{~cm})$ & $87.9 \pm 9.1$ & $85.4 \pm 10.3$ & 0.000 \\
\hline $\mathrm{SBP}(\mathrm{mmHg})$ & $133.7 \pm 16.1$ & $135.4 \pm 15.8$ & 0.013 \\
\hline $\mathrm{DBP}(\mathrm{mmHg})$ & $78.6 \pm 8.9$ & $77.4 \pm 8.6$ & 0.002 \\
\hline FPG (mmol/L, Mean) & $6.2 \pm 1.6$ & $6.3 \pm 1.8$ & 0.268 \\
\hline FPG $(\text { mmol/L, Median })^{a}$ & 5.45 & 5.51 & 0.268 \\
\hline TG $(\mathrm{mmol} / \mathrm{L})$ & $1.5 \pm 0.9$ & $1.6 \pm 0.9$ & 0.000 \\
\hline $\mathrm{TC}(\mathrm{mmol} / \mathrm{L})$ & $5.2 \pm 1.0$ & $5.8 \pm 1.0$ & 0.000 \\
\hline
\end{tabular}

Categorical data were described as $\mathrm{n}(\%)$ and continuous data were described as means $\pm S D$

$B M I$ body mass index, WC waist circumference, $S B P$ systolic blood pressure, $D B P$ diastolic blood pressure, $F P G$ fasting plasma glucose, $T G$ triglyceride, $T C$ total cholesterol

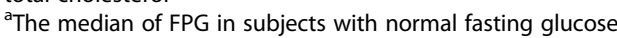
level $(<6.1 \mathrm{mmol} / \mathrm{L})$

$P$ values $<0.05$ were considered significant 
associations of hyperglycemic status with SBP and but not DBP (Table 2).

The median of FPG was $5.45 \mathrm{mmol} / \mathrm{L}$ in men, and $5.51 \mathrm{mmol} / \mathrm{L}$ in women respectively in NFG group (Table 3). NFG group was further divided into two subgroups according to the median FPG level by sex. Even in the normal range of FPG, using below the median level of FPG as the reference, when adjusting for age, smoking and alcohol consumption (Model 1), higher FPG above the median was still significantly associated with a higher prevalence of hypertension in both gender, with OR of $1.93(95 \% \mathrm{CI}, 1.60-2.34)\left(R^{2}=0.028, P=\right.$ $0.000)$ in men and $1.96(95 \% \mathrm{CI}, 1.51-2.54)\left(R^{2}=0.033\right.$, $P=0.000)$ in women respectively. After further adjusting for BMI, WC, TG and TC (Model 2), the association between higher FPG and the prevalence of hypertension was attenuated but remained statistically significant (OR 1.24 [95 \% CI, 0.85-1.80], $R^{2}=0.114, P=0.023$ in men and 1.61 [95 \% CI, 1.12-2.30], $R^{2}=0.082, P=0.010$ in women respectively). Similar associations were found between higher FPG levels and higher SBP in both genders. However, we did not find any association between higher FPG and higher DBP in both genders in Model 2.

Table 4 showed the independent risk factors for SBP and DBP in whole sample and in individuals without hypoglycemic nor antihypertensive drugs $(n=924)$ by stepwise linear regression analysis. After adjusting for sex, age, smoking, alcohol consumption, BMI, WC, TC, and TG, FPG levels were significantly associated with SBP in both samples $\left(\beta=0.10, R^{2}=0.013, P<0.01\right.$ in whole sample and $\beta=0.12, R^{2}=0.013, P<0.01$ in individuals without hypoglycemic or antihypertensive drugs respectively). As for DBP, FPG levels were also associated with DBP in individuals without hypoglycemic or antihypertensive drugs $\left(\beta=0.08, R^{2}=0.006, P<0.05\right)$.

\section{Association of BP and risk of hyperglycemia}

We explored the possible effect of high-normal BP and hypertension on the risk of IFG and DM by using multiple logistic regression analysis (Table 5). After adjusting for age, sex, smoking and alcohol consumption, when compared with the normal BP group, hypertensives had a significantly higher prevalence of IFG (OR 3.92 [95 \% CI, 2.17-7.10], $P<0.01)$, and DM (2.83 [95 \% CI, 1.83-4.38], $P<0.01)$ respectively, and subjects with high-normal BP had a similarly increased prevelance in IFG and DM (OR 2.07 [95 \% CI, 1.13-3.78], $P<0.05$, and OR 1.78 [95 \% CI, 1.14-2.76], $P<0.05$, respectively) (Table 5, Model 1). When further adjusting for BMI, WC, TG, and TC, the associations between hypertension and IFG and DM remained statistically significant, though attenuated (OR 3.17 [95 \% CI, 1.70-5.68], $P<0.01$, and 1.93 [95\% CI, 1.22-3.04], $P<0.01$, respectively). Similar associations were also seen between high-normal BP and IFG, but not DM (Table 5, Model 2).

\section{Discussion}

The close relationship between diabetes and hypertension has been recognized since the 1980s $[6,10]$, but how much this effect varies by race-ethnicity, age or levels of traditional risk factors is uncertain. The extent to which glucose concentration is associated with elevated blood pressure is also uncertain. The data for pure elders in China is more limited. In our present study, we aimed to explore the association of diabetes and FPG concentration with hypertension or high-normal BP in a select groups of elderly subjects in China. We found that, compared with subjects with NFG, subjects with IFG and previously-diagnosed DM had a higher prevalence of hypertension. Even among the subjects with NFG, higher FPG was still associated with a higher prevalence of hypertension after adjusting for covariates such as age, smoking, alcohol consumption, BMI, WC, TG, and TC level. FPG was an independent factor of systolic and diastolic BP. Conversely, multiple analyses revealed that subjects with hypertension also had a higher prevalence of IFG and DM.

Our study is comply with other studies that have indicated an increased risk for hypertension and other cardiovascular risk factors in diabetic individuals as well as in impaired glucose regulation than those with NFG $[6,7,17,18]$. Our study extends this observation by illustrating that a high but normal FPG level was also a risk factor for hypertension in elderly Chinese subjects,

Table 2 Logistic regression analysis of association of hyperglycemia status with risk of hypertension ${ }^{a}$

\begin{tabular}{|c|c|c|c|c|c|c|c|c|}
\hline & \multicolumn{2}{|c|}{$\mathrm{SBP} \geq 140 \mathrm{mmHg}$} & \multicolumn{2}{|c|}{$\mathrm{DBP} \geq 90 \mathrm{mmHg}$} & \multicolumn{2}{|c|}{ Total Hypertension } & \multicolumn{2}{|c|}{ New-onset Hypertension } \\
\hline & OR $(95 \% \mathrm{Cl})$ & $P$ value & OR $(95 \% \mathrm{Cl})$ & $P$ value & OR $(95 \% \mathrm{Cl})$ & $P$ value & OR $(95 \% \mathrm{Cl})$ & $P$ value \\
\hline NFG & 1 & - & 1 & - & 1 & - & 1 & - \\
\hline IFG & $1.89(1.46-2.45)$ & 0.000 & $1.31(0.94-1.84)$ & 0.111 & $1.81(1.39-2.35)$ & 0.000 & $1.68(1.18-2.41)$ & 0.004 \\
\hline New-onset DM & $1.44(0.99-1.65)$ & 0.053 & $1.23(0.78-1.95)$ & 0.375 & $1.35(0.93-1.94)$ & 0.115 & $1.49(0.91-2.42)$ & 0.113 \\
\hline Previously-diagnosed DM & $1.46(1.13-1.87)$ & 0.003 & $1.02(0.72-1.44)$ & 0.913 & $1.40(1.09-1.80)$ & 0.009 & $0.90(0.61-1.33)$ & 0.592 \\
\hline
\end{tabular}

NFG normal fasting glucose, IFG impaired fasting glucose, New-onset DM, newly diagnosed diabetes mellitus; Previously-Diagnosed DM, previously diagnosed diabetes mellitus; New-onset hypertension, newly diagnosed hypertension; OR (95\% Cl), odds ratio $(95 \%$ confidence index); other abbreviations see Table 1 ${ }^{a}$ Adjusted for sex, age, smoking, alcohol consumption, BMI, TG and TC level

$P$ values $<0.05$ were considered significant 
Table 3 Logistic regression analysis of risk of hypertension in subjects with NFG (above vs. below the median fasting glucose level ${ }^{\mathrm{a}}$ )

\begin{tabular}{|c|c|c|c|c|c|c|}
\hline & \multicolumn{2}{|l|}{ Men } & \multirow[b]{2}{*}{ Adjusted $R^{2}$} & \multicolumn{2}{|l|}{ Women } & \multirow[b]{2}{*}{ Adjusted $\mathrm{R}^{2}$} \\
\hline & $\begin{array}{l}\text { OR }(95 \% \mathrm{Cl} \text {, below vs above } \\
\text { the median \$) }\end{array}$ & $P$ value\# & & $\begin{array}{l}\text { OR }(95 \% \mathrm{Cl} \text {, below vs above } \\
\text { the median \$) }\end{array}$ & $P$ value ${ }^{\#}$ & \\
\hline \multicolumn{7}{|c|}{ Total Hypertension } \\
\hline Model 1 & $1.93(1.60-2.34)$ & 0.000 & 0.028 & $1.96(1.51-2.54)$ & 0.000 & 0.033 \\
\hline Model 2 & $1.24(0.85-1.80)$ & 0.023 & 0.114 & $1.61(1.12-2.30)$ & 0.010 & 0.082 \\
\hline \multicolumn{7}{|c|}{$\mathrm{SBP} \geq 140 \mathrm{mmHg}$} \\
\hline Model 1 & $2.04(1.54-2.70)$ & 0.000 & 0.022 & $2.03(1.56-2.65)$ & 0.000 & 0.026 \\
\hline Model 2 & $1.50(1.07-2.10)$ & 0.019 & 0.058 & $1.27(0.93-1.74)$ & 0.013 & 0.071 \\
\hline \multicolumn{7}{|c|}{$\mathrm{DBP} \geq 90 \mathrm{mmHg}$} \\
\hline Model 1 & $1.21(0.84-1.75)$ & 0.301 & 0.022 & $1.67(1.12-2.67)$ & 0.011 & 0.063 \\
\hline Model 2 & $0.72(0.46-1.15)$ & 0.167 & 0.048 & $1.35(0.85-2.12)$ & 0.201 & 0.015 \\
\hline
\end{tabular}

Abbreviations see Tables 1 and 2

Model 1, adjusted for age, smoking and alcohol using

Model 2, adjusted for age, smoking, alchol using, BMI, WC, TG and TC level

${ }^{a}$ The median fasting glucose level was $5.45 \mathrm{mmol} / \mathrm{L}$ in men and $5.51 \mathrm{mmol} / \mathrm{L}$ in women respectively

$P$ values $<0.05$ were considered significant

and this relation was independent of other traditional cardiovascular risk factors. What's more, we found that elevated FPG was independently associated with an increased risk of SBP and DBP. This is also in line with two recent studies $[19,20]$. In Di Bonito P's study among Southern European Caucasian children and adolescents (age 6-16 years), they found that subjects with highnormal FPG (83-99 $\mathrm{mg} / \mathrm{dL}$ ) had 1.57-2.23 times the risk for hypertension when compared with subjects with low-normal FPG ( $\leq 82 \mathrm{mg} / \mathrm{dL}$ ) independent of BMI [19]. In a cohort study of a Japanese population (age 20-80 years), Y Heianza found that elevated concentration of FPG in normal range $(<4.9 \mathrm{mmol} / \mathrm{L}$ vs. $4.9-5.6 \mathrm{mmol} / \mathrm{L})$ was associated with higher risk of developing hypertension (OR 1.35-1.39) during a 5-year follow-up after adjusting for age and gender [20].

Our data also matches with other epidemiological data demonstrating that basal $\mathrm{BP}$ and $\mathrm{BP}$ progression are strong and independent predictors of incident hyperglycemia $[7,10-12,18]$, and is also consistent with clinical trial data demonstrating that lower BP are associated with lower risk of cardiovascular diseases [13]. In the Women's Health Study in the USA by David Conen et al, a baseline BP of 130-139/85-89 mmHg and hypertension will increase risk of incident Type 2 diabetes in the following 10 years by 1.45-2.03 times [7]. In a recent study of Chinese subjects in Hong Kong aged over 18 years, Sau NF found that subjects with IFG were

Table 4 Stepwise linear regression analysis of risk factors for SBP and DBP

\begin{tabular}{|c|c|c|c|c|c|c|c|c|}
\hline & \multicolumn{4}{|c|}{ All subjects $(n=2092)$} & \multicolumn{4}{|c|}{ Subjects without hypoglycemic or antihypertensive drugs $(n=924)$} \\
\hline & \multicolumn{2}{|l|}{ SBP } & \multicolumn{2}{|l|}{ DBP } & \multicolumn{2}{|l|}{ SBP } & \multicolumn{2}{|l|}{$\mathrm{DBP}$} \\
\hline & $\bar{\beta}$ & $R^{2}$ & $\bar{\beta}$ & $R^{2}$ & $\bar{\beta}$ & $\mathrm{R}^{2}$ & $\bar{\beta}$ & $\mathrm{R}^{2}$ \\
\hline BMI $\left(\mathrm{kg} / \mathrm{m}^{2}\right)$ & $0.15^{* *}$ & 0.034 & $0.13^{* *}$ & 0.032 & $0.15^{* *}$ & 0.028 & 0.42 & - \\
\hline FPG (mmol/L) & $0.10^{* *}$ & 0.013 & 0.022 & - & $0.12^{* *}$ & 0.013 & $0.08^{*}$ & 0.006 \\
\hline Age (years) & $0.09^{* *}$ & 0.008 & $-0.16^{* *}$ & 0.019 & $0.07^{*}$ & 0.004 & $-0.17^{* *}$ & 0.026 \\
\hline $\begin{array}{l}\text { Smoking } \\
\text { (yes/no) }\end{array}$ & -0.07 & - & -0.03 & - & $-0.13^{*}$ & 0.012 & -0.23 & - \\
\hline $\begin{array}{l}\text { Alcohol consumption } \\
\text { (yes/no) }\end{array}$ & $0.06^{* *}$ & 0.003 & 0.021 & - & $0.07^{*}$ & 0.004 & 0.026 & - \\
\hline TC (mmol/L) & $0.05^{*}$ & 0.003 & $0.09^{* *}$ & 0.005 & 0.04 & - & 0.061 & - \\
\hline TG $(\mathrm{mmol} / \mathrm{L})$ & $0.07^{* *}$ & 0.002 & $0.05^{*}$ & 0.007 & 0.01 & - & -0.34 & - \\
\hline Male (vs.Female) & 0.02 & - & -0.09 & - & 0.03 & - & 0.109 & - \\
\hline $\mathrm{WC}(\mathrm{mmol} / \mathrm{L})$ & 0.57 & - & 0.61 & - & 0.09 & - & $0.14^{* *}$ & 0.021 \\
\hline
\end{tabular}

Abbreviations see Table 1

${ }^{*} P$ value $<0.05 ;{ }^{*} P$ value $<0.01$ 
Table 5 Multiple logistic regression analysis of risk of IFG and DM

\begin{tabular}{|c|c|c|c|c|}
\hline & \multicolumn{2}{|l|}{ IFG } & \multicolumn{2}{|l|}{$\mathrm{DM}$} \\
\hline & OR $(95 \% \mathrm{Cl})$ & Adjusted $R^{2}$ & OR $(95 \% \mathrm{Cl})$ & Adjusted $R^{2}$ \\
\hline Model $1^{\text {a }}$ & & 0.045 & & 0.028 \\
\hline Age (years) & $1.01(0.99-1.03)$ & & $1.00(0.99-1.02)$ & \\
\hline Male (vs. female) & $0.95(0.73-1.25)$ & & $0.99(0.78-1.24)$ & \\
\hline Smoking(yes/no) & $0.92(0.68-1.08)$ & & $1.01(0.85-1.21)$ & \\
\hline Alcohol consumption (yes/no) & $1.06(0.84-1.43)$ & & $0.93(0.76-1.41)$ & \\
\hline High-normal BP & $2.07(1.13-3.78)^{*}$ & & $1.78(1.14-2.76)^{*}$ & \\
\hline \multicolumn{5}{|l|}{ (vs. normal BP) } \\
\hline Hypertension & $3.92(2.17-7.10)^{* *}$ & & $2.83(1.83-4.38)^{* *}$ & \\
\hline \multicolumn{5}{|l|}{ (vs. normal BP) } \\
\hline Model $2^{b}$ & & 0.095 & & 0.140 \\
\hline Age (years) & $1.01(0.99-1.03)$ & & $1.01(0.99-1.03)$ & \\
\hline Male (vs. female) & $0.96(0.71-1.30)$ & & $0.97(0.81-1.18)$ & \\
\hline Smoking(yes/no) & $0.83(0.65-1.05)$ & & $0.92(0.74-1.14)$ & \\
\hline Alcohol consumption (yes/no) & $1.09(0.86-1.39)$ & & $0.99(0.77-1.28)$ & \\
\hline BMI $\left(\mathrm{kg} / \mathrm{m}^{2}\right)$ & $1.02(0.95-1.09)$ & & $1.04(0.99-1.10)^{* *}$ & \\
\hline $\mathrm{WC}(\mathrm{mmol} / \mathrm{L})$ & $1.03(1.00-1.06)^{*}$ & & $1.04(1.02-1.06)^{* *}$ & \\
\hline TG $(\mathrm{mmol} / \mathrm{L})$ & $1.42(1.22-1.66)^{* *}$ & & $1.55(1.36-1.77)^{* *}$ & \\
\hline $\mathrm{TC}(\mathrm{mmol} / \mathrm{L})$ & $0.96(0.84-1.10)$ & & $0.95(0.85-1.06)$ & \\
\hline High-normal BP & $1.87(1.03-3.44)^{*}$ & & $1.46(0.94-2.31)$ & \\
\hline \multicolumn{5}{|l|}{ (vs. normal BP) } \\
\hline Hypertension & $3.17(1.70-5.68)^{* *}$ & & $1.93(1.22-3.04)^{* *}$ & \\
\hline (vs. normal BP) & & & & \\
\hline
\end{tabular}

Abbreviations see Tables 1 and 2

Normal BP, SBP $<120 \mathrm{mmHg}$ and DBP $<80 \mathrm{mmHg}$ and not using antihypertensive medication; high-normal BP, SBP $120-139 \mathrm{mmHg}$ or DBP $80-90 \mathrm{mmHg}$ hypertension, $\mathrm{SBP} \geq 140 \mathrm{mmHg}$ and/or $\mathrm{DBP} \geq 90 \mathrm{mmHg}$ or using antihypertensive medication

${ }^{a}$ Model 1: Logistic regression analysis with IFG and DM as dependent variable respectively, and age, male (vs. female), smoking, alcohol consumption, and high-normal BP (vs. normal BP) and hypertension (vs. normal BP) as independent variables

${ }^{\mathrm{b}}$ Model 2: Model $1+$ BMI, WC, TG and TC

* $P$ value $<0.05 ; * P$ value $<0.01$

more likely to develop diabetes within 5 years if they were hypertensive $(\mathrm{aHR}=1.44)$ [11]. A large Japanese cohort study also showed that having both high-normal $\mathrm{BP}$ and hypertension in middle age was associated with increased risk of developing diabetes [9]. In our present study, we also found high-normal BP associated with risk of IFG after adjusting for conventional risk factors.

Although the association between hypertension and hyperglycemia has long been discussed, the underlying biological basis mediating this clinical association remains unclear. Hyperinsulinemia, an important component of the metabolic syndrome, may be one of the main factors [21]. Insulin resistance, which further contributes to hyperinsulinemia, often progresses to Type 2 diabetes [22]. In addition, the resistance in the hemodynamic properties of insulin may impair the blood flow in peripheral tissues, which indirectly contributes to the development of the atherogenic dysglycemia and dyslipidemia [23]. Hyperinsulinemia may directly contribute to elevation of blood pressure by increasing renal sodium retention [24] and enhancing sympathetic nervous system activity [25], whereas chronic sympathetic nervous system overactivity may contribute to a further increase of insulin resistance creating a vicious circle that may lead to the development of hypertension and diabetes. In addition, insulin resistance is also associated with a decreased vasodilatory response to insulin in peripheral tissue $[26,27]$ and an increased vasoconstrictor response to various vasopressors $[28,29]$, which mainly results the increase of systolic blood pressure. The pathophysiological mechanism linking insulin and hypertension is complex and still needs to be fully elucidated.

Our present study adds to the literature by demonstrating that hyperglycemia is closely correlated with hypertension in a population of the elderly. We were able to explore the associations between blood glucose levels and BP in a relative large, well-defined cohort. However, several potential limitations of the study merit 
discussion. First, because of the observational nature of the study, we cannot infer causality from our present data. Second, lack of evaluation of postprandial blood glucose level and repeated FPG measurement should underestimate the prevalence of diabetes in this population. As this was a survey based on the elderly population, postprandial blood glucose measurement may pose certain problems for the elderly, as they would need to wait $2 \mathrm{~h}$ for venous draw blood after a meal. Third, although multiple potential confounders have been adjusted for, we cannot completely rule out the residual confounders attributed to the inaccurate measurement of confounders, or some unmeasured confounders.

\section{Conclusions}

Our study suggests that hyperglycemia as well as a high but normal FPG level was associated with a higher prevalence of hypertension independent of other cardiovascular risk factors among elderly Chinese. On the other hand, hypertension, even high-normal BP, was also associated with a higher prevalence of hyperglycemia. Further studies are needed to explore the relationship between hyperglycemia and hypertension in a longitudinal setting.

\section{Abbreviations}

$\mathrm{BP}$, blood pressure; TG, triglyceride; HDL-c, high-density lipoprotein cholesterol; DM, diabetes mellitus; FPG, fasting plasma glucose; AIDS, acquired immune deficiency syndrome; SBP, systolic blood pressure; DBP, diastolic blood pressure; NFG, normal fasting glucose; IFG, impaired fasting glucose; BMI, body mass index; TC, total cholesterol

\section{Acknowledgments}

We were grateful to the participants, physicians and nurses in the Department of endocrinology of Shanghai East hospital and Shanghai Puxing Community Health-Care Center for taking part in this study.

\section{Funding}

This study was funded by Key Disciplines Group Construction Project of Pudong Health Bureau of Shanghai (Grant No.PWZxkq2010-04), Key Specialty Construction Project of Pudong Health and Family Planning Commission of Shanghai (Grant No.PWZz2013-04) and Project of Science and Technology of Pudong Health and Family Planning Commission of Shanghai (Grant No.PW2013c-11).

\section{Availability of data and materials}

This research was based on a public health examination for the elders in the 11 communities of Shanghai Pudong New Area. As the dataset contained direct identifiers of the participants and the informed consent for publication was not obtained, we could not share it according to the law of the institutional review board of Shanghai East Hospital.

\section{Authors' contributions}

BF was the principal investigator (PI). He designed the study and oversaw the project implementation, participated in data collection, analyses and interpretation and writing publications. QY and DS participated in study design and participated in data collection, data analyses and interpretation and writing publications. $X \mathrm{~L}$ participated in the design of the study and performed the statistical analysis. GC, QZ, LL and CG conceived of the study, and participated in its coordination and helped to draft the manuscript. All authors read and approved the final manuscript.

\section{Authors' information}

Professor Bo Feng, the Ph.D supervisor, the member of the Chinese Diabetes Society; the Vice Chairman of Shanghai Diabetes Association; the member of Shanghai Diabetes Rehabilitation Association; the Director of the Committee of Endocrinology, Shanghai Pudong New District.

\section{Competing interests}

The authors declare that they have no conflict of interest to declare.

\section{Consent for publication}

Not applicable.

\section{Ethical approval and consent to participate}

Written informed consent was obtained from all participants. This study was approved by the institutional review board of Shanghai East Hospital and complied with the Declaration of Helsinki.

\section{Author details}

${ }^{1}$ Department of Endocrinology, Shanghai East Hospital, Tongji University School of Medicine, 150 Jimo Road, Shanghai 200120, China. ${ }^{2}$ Puxing Community Health-Care Center, Pudong New District, 250 GuiChang Road, Shanghai 200136, China.

Received: 22 February 2016 Accepted: 22 June 2016

Published online: 13 July 2016

\section{References}

1. Grundy SM, Cleeman II, Daniels SR, Donato KA, Eckel RH, Franklin BA, et al. Diagnosis and management of the metabolic syndrome: an American Heart Association/NationalHeart, Lung, and Blood Institute scientific statement. Circulation. 2005:112:2735-52.

2. Lakka HM, Laaksonen DE, Lakka TA, Niskanen LK, Kumpusalo E, Tuomilehto J, et al. The metabolic syndrome and total and cardiovascular disease mortality in middle-aged men. JAMA. 2002;288:2709-16.

3. Isomaa B, Almgren P, Tuomi T, Forsén B, Lahti K, Nissén M, et al. Cardiovascular morbidity and mortality associated with the metabolic syndrome. Diabetes Care. 2001:24:683-9.

4. Emerging Risk Factors Collaboration, Sarwar N, Gao P, Seshasai SR, Gobin R, Kaptoge $\mathrm{S}$, et al. Diabetes mellitus, fasting blood glucose concentration, and risk of vascular disease: a collaborative meta-analysis of 102 prospective studies. Lancet. 2010:375:2215-22.

5. Stamler J, Vaccaro O, Neaton JD, Wentworth D. Diabetes, other risk factors, and 12-yr cardiovascular mortality for men screened in the Multiple Risk Factor Intervention Trial. Diabetes Care. 1993:16:434-4.

6. Hypertension in Diabetes Study (HDS): I. Prevalence of hypertension in newly presenting type 2 diabetic patients and the association with risk factors for cardiovascular and diabetic complications. J Hypertens. 1993;11:309-17.

7. Yang $Z$, Xing $X$, Xiao J, Lu J, Weng J, Jia W, et al. Prevalence of cardiovascular disease and risk factors in the Chinese population with impaired glucose regulation: the 2007-2008 China national diabetes and metabolic disorders study. Exp Clin Endocrinol Diabetes. 2013;121:372-74.

8. Conen D, Ridker PM, Mora S, Buring JE, Glynn RJ, et al. Blood pressure and risk of developing type 2 diabetes mellitus: the Women's Health Study. Eur Heart J. 2007;28:2937-43.

9. Golden SH, Wang NY, Klag MJ, Meoni LA, Brancati FL. Blood pressure in young adulthood and the risk of type 2 diabetes in middle age. Diabetes Care. 2003;26:1110-5.

10. Hayashi T, Tsumura K, Suematsu C, Endo G, Fujii S, Okada K. High normal blood pressure, hypertension, and the risk of type 2 diabetes in Japanese men. The Osaka Health Survey. Diabetes Care. 1999;22:1683-87.

11. Wei GS, Coady SA, Goff Jr DC, Brancati FL, Levy D, Selvin E, et al. Blood pressure and the risk of developing diabetes in African Americans and whites: ARIC, CARDIA, and the Framingham heart study. Diabetes Care. 2011:34:873-9.

12. Fu SN, Luk W, Wong CK, Cheung KL. Progression from impaired fasting glucose to type 2 diabetes mellitus among Chinese subjects with and without hypertension in a primary care setting. J Diabetes. 2014;6:438-46.

13. Lewington S, Clarke R, Qizilbash N, Peto R, Collins R, Prospective Studies Collaboration. Age-specific relevance of usual blood pressure to vascular mortality: a meta-analysis of individual data for one million adults in 61 prospective studies. Lancet. 2002;360:1903-13. 
14. Yan Q, Sun D, Li X, Zheng Q, Li L, Gu C, Feng B. Neck circumference is a valuable tool for identifying metabolic syndrome and obesity in Chinese elder subjects: a community-based study. Diabetes Metab Res Rev. 2014;30:69-76.

15. Chobanian AV, Bakris GL, Black HR, Cushman WC, Green LA, Izzo JL, et al. Seventh report of the Joint National Committee on prevention, detection, evaluation, and treatment of high blood pressure. Hypertension. 2003;42:1206-52.

16. Alberti KG, Zimmet PZ. Definition, diagnosis and classification of diabetes mellitus and its complications. Part 1: diagnosis and classification of diabetes mellitus provisional report of a WHO consultation. Diabet Med. 1998;15:539-53.

17. Williams DE, Cadwell BL, Cheng YJ, Cowie CC, Gregg EW, Geiss LS, et al. Prevalence of impaired fasting glucose and its relationship with cardiovascular disease risk factors in US adolescents, 1999-2000. Pediatrics. 2005;116:1122-6.

18. Chen G, McAlister FA, Walker RL, Hemmelgarn BR, Campbell NR Cardiovascular outcomes in Framingham participants with diabetes: the importance of blood pressure. Hypertension. 2011;57:891-7.

19. Di Bonito P, Sanguigno E, Forziato C, Saitta F, lardino MR, Capaldo B. Fasting plasma glucose and clustering of cardiometabolic risk factors in normoglycemic outpatient children and adolescents. Diabetes Care. 2011;34:1412-14

20. Heianza Y, Arase Y, Kodama S, Hsieh SD, Tsuji H, Saito K, et al. Fasting glucose and $\mathrm{HbA1C}$ levels as risk factors for the development of hypertension in Japanese individuals: Toranomon hospital heath management center study 16(TOPICS 16). J Hum Hypertens. 2015;29:254-9.

21. Lambert GW, Straznicky NE, Lambert EA, Dixon JB, Schlaich MP. Sympathetic nervous activation in obesity and the metabolic syndrome-causes, consequences and therapeutic implications. Pharmacol Ther. 2010;126:159-72.

22. Dimitriadis G, Mitrou P, Lambadiari V, Maratou E, Raptis SA. Insulin effects inmuscle and adipose tissue. Diabetes Res Clin Pract. 2011;93 Suppl 1:S52-9.

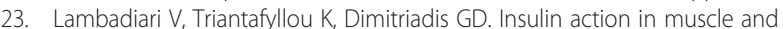
adipose tissue in type 2 diabetes: The significance of blood flow. World J Diabetes. 2015;6:626-33.

24. Chávez-Canales M, Arroyo JP, Ko B, Vázquez N, Bautista R, Castañeda-Bueno $\mathrm{M}$, et al. Insulin increases the functional activity of the renal $\mathrm{NaCl}$ cotransporter. J Hypertens. 2013;31:303-11.

25. Reaven GM. Role of insulin resistance in human disease. Diabetes. 1988:37:1595-607.

26. Doronzo G, Russo I, Mattiello L, Anfossi G, Bosia A, Trovati M. Insulin activates vascular endothelial growth factor in vascular smooth muscle cells: influence of nitric oxide and of insulin resistance. Eur J Clin Invest. 2004;34:664-73.

27. Anfossi G, Russo I, Doronzo G, Trovati M. Contribution of insulin resistance to vascular dysfunction. Arch Physiol Biochem. 2009;115:199-217.

28. Jia G, DeMarco VG, Sowers JR. Insulin resistance and hyperinsulinaemia in diabetic cardiomyopathy. Nat Rev Endocrinol. 2016;12:144-53.

29. Zhou MS, Liu C, Tian R, Nishiyama A, Raij L. Skeletal muscle insulin resistance in salt-sensitive hypertension: role of angiotensin II activation of NFkB. Cardiovasc Diabetol. 2015;14:45

\section{Submit your next manuscript to BioMed Central and we will help you at every step:}

- We accept pre-submission inquiries

- Our selector tool helps you to find the most relevant journal

- We provide round the clock customer support

- Convenient online submission

- Thorough peer review

- Inclusion in PubMed and all major indexing services

- Maximum visibility for your research

Submit your manuscript at www.biomedcentral.com/submit

) Biomed Central 